\title{
Tlx, an Orphan Nuclear Receptor, Regulates Cell Numbers and Astrocyte Development in the Developing Retina
}

\author{
Takaya Miyawaki, ${ }^{1}$ Akiyoshi Uemura, ${ }^{2}$ Mari Dezawa, ${ }^{3}$ Ruth T. Yu, ${ }^{4}$ Chizuka Ide, ${ }^{3}$ Shinichi Nishikawa, ${ }^{2}$ \\ Yoshihito Honda, ${ }^{1}$ Yasuto Tanabe, ${ }^{5}$ and Teruyo Tanabe ${ }^{1}$ \\ ${ }^{1}$ Department of Ophthalmology, Kyoto University Graduate School of Medicine, Kyoto 606-8507, Japan, ${ }^{2}$ RIKEN Center for Developmental Biology, Kobe, \\ Hyogo 650-0047, Japan, ${ }^{3}$ Department of Anatomy and Neurobiology, Kyoto University Graduate School of Medicine, Kyoto 606-8501, Japan, ${ }^{4}$ Gene \\ Expression Laboratory, The Salk Institute, La Jolla, California 92037, and ${ }^{5}$ Mitsubishi Kagaku Institute of Life Sciences, Precursory Research for Embryonic \\ Science and Technology, Neural Organization Research Team, Tokyo 194-8511, Japan
}

Tlx belongs to a class of orphan nuclear receptors that underlies many aspects of neural development in the CNS. However, the fundamental roles played by Tlx in the control of eye developmental programs remain elusive. By using Tlx knock-out (K0) mice, we show here that Tlx is expressed by retinal progenitor cells in the neuroblastic layer during the period of retinal layer formation, and it is critical for controlling the generation of appropriate numbers of retinal progenies through the activities of cell cycle-related molecules, cyclin D1 and $\mathrm{p} 27^{\mathrm{Kip} 1}$. Tlx expression is restricted to Müller cells in the mature retina and appears to control their proper development. Furthermore, we show that Tlx is expressed by immature astrocytes that migrate from the optic nerve onto the inner surface of the retina and is required for their generation and maturation, as assessed by honeycomb network formation and expression of R-cadherin, a critical component for vasculogenesis. The impaired astrocyte network formation on the inner retinal surface is accompanied by the loss of vasculogenesis in Tlx KO retinas. Our studies thus indicate that Tlx underlies a fundamental developmental program of retinal organization and controls the generation of the proper numbers of retinal progenies and development of glial cells during the protracted period of retinogenesis.

Key words: Tlx; astrocyte; retinal progenitor cells; cyclinD1; $27^{\mathrm{Kip} 1}$; nuclear receptor; cell proliferation; vasculogenesis

\section{Introduction}

An early and fundamental step of the developmental programs that culminate in retinal organization is the spatial and temporal control of the generation of distinct retinal subtypes in appropriate numbers (Livesey and Cepko, 2001; Marquardt, 2003). Distinct cell types intrinsic to the retina are generated from the retinal progenitor cells (RPCs) in the neuroblastic layer (NBL) and establish the three major nuclear layers of the retina: ganglion cell layer (GCL), inner nuclear layer (INL), and outer nuclear layer $(\mathrm{ONL})$. In contrast, astrocytes that are initially extrinsic to the retina are generated within the optic nerve, migrate onto the inner surface of the retina, and participate in the organization of retinal cytoarchitectures (Chu et al., 2001). Many advances have been made in identifying and characterizing molecules that control the specification of each neuronal identity, however, the mechanisms by which relative cell numbers of neuronal progenies comprising each nuclear layer are determined remain obscure (Dyer and Cepko, 2001b; Zhang and Yang, 2001; Ohnuma

\footnotetext{
Received Dec. 1, 2003; revised July 27, 2004; accepted July 27, 2004.

This work was supported in part by grants from the Ministry of Education, Culture, Sports, Science, and Technology of Japan. We thank K. Umesono and R. M. Evans for the gift of T/x KO mice. We also thank T. Noda, T. Akagi, Y. Ueda, M. Kondo, and S. Ueno for technical assistance and M. Takahashi and J. C. Saari for the kind gifts of antibodies. We are grateful to R. Kageyama for his thoughtful comments on this work.

Correspondence should be addressed to Dr. Teruyo Tanabe, Department of Ophthalmology, Kyoto University Graduate School of Medicine, 54 Shogoin Kawahara-cho, Sakyo-ku, Kyoto 606-8507, Japan. E-mail: tanabet@kuhp.kyoto-u.ac.jp.

D01:10.1523/JNEUROSCI.2235-04.2004

Copyright $\odot 2004$ Society for Neuroscience $\quad$ 0270-6474/04/248124-11\$15.00/0
}

et al., 2002; Dyer, 2003). Moreover, how the development of two major retinal glial subtypes, namely Müller cells and astrocytes, is controlled has yet to be elucidated.

Previous studies indicate that nuclear receptors play crucial roles in the developmental and physiological processes in a wide variety of tissues (Mangelsdorf et al., 1995; Thummel, 1995). In the developing eye, studies on the photoreceptor specific nuclear receptor (PNR) showed that $\mathrm{PNR}$ is responsible for the enhanced $\mathrm{S}$ cone syndrome in humans (Haider et al., 2000). Another study showed that retinoid-related orphan receptor $\beta(\operatorname{ROR} \beta)$ is expressed in the NBL and appears to regulate progenitor cell proliferation (Chow et al., 1998). These studies led to the idea that, nuclear receptors, in addition to basic helix-loop-helix (bHLH) and homeodomain transcription factors (Cepko, 1999), might play fundamental roles in the control of progenitor cell proliferation as well as the differentiation and maintenance of retinal progenies.

Tlx belongs to the class of orphan nuclear receptors and has been implicated in the control of neural cytoarchitectural organization (Yu et al., 1994; Monaghan et al., 1997) The null mutation of Tlx results in optic nerve hypoplasia, retinal degeneration, and diminished vascularization in the developing eye ( $\mathrm{Yu}$ et al., 2000; Young et al., 2002). However, how Tlx contributes to the development of retinal organization remained to be determined. We show here that Tlx is expressed by RPCs and is required for the generation of appropriate numbers of each neuronal progeny. Tlx is also expressed by two major glial subtypes in the eye, 
Müller cells and astrocytes, and appears to be crucial for the acquisition and maintenance of their mature phenotypes. Moreover, Tlx appears to be critical for the control of generating appropriate numbers of retinal astrocytes and is required for the expression of R-cadherin, a critical component of vasculogenesis, in astrocytes, that might account for the loss of retinal vasculogenesis in Tlx mutant retinas.

\section{Materials and Methods}

Mice. Heterozygous Tlx knock-out (KO) mice (Yu et al., 1994) were mated to obtain offspring in house in an environmentally controlled room under the International Guiding Principles For Biomedical Research Involving Animals and Guidelines of Animal Research Committee (Graduate School of Medicine, Kyoto University). Noon of the day on which the vaginal plug was detected was designated as embryonic day 0.5 (E0.5). Littermates were genotyped by PCR to identify wild-type, heterozygotes, and homozygotes used for the analyses.

$X$-gal staining. Eyes were removed from embryos or postnatal mice and fixed with $2.5 \%$ glutaraldehyde in $0.1 \mathrm{M}$ PBS at $4^{\circ} \mathrm{C}$ overnight. Samples were then equilibrated in $25 \%$ sucrose in PBS and embedded in OCT compound (Sakura Finetek, Torrance, CA). Frozen sections $(20 \mu \mathrm{m}$ in thickness) were mounted onto MAS-coated glass slides (Matsunami, Osaka, Japan). X-gal staining procedures were performed as described (Gouras et al., 1991).

Immunohistochemistry. Early-stage embryos $(\sim$ E13.5) and the eyes derived from late-stage embryos or postnatal mice were fixed with $4 \%$ paraformaldehyde (PFA) in $0.1 \mathrm{~m}$ PBS, pH 7.4. Samples were washed in PBS three times for $5 \mathrm{~min}$, incubated in 25\% sucrose in PBS, and embedded in OCT compound. Frozen sections ( $20 \mu \mathrm{m}$ in thickness) were postfixed with 4\% PFA for $3 \mathrm{~min}$ and washed in PBS three times for $3 \mathrm{~min}$ each. For immunohistochemical procedures, sections were first incubated with blocking solution containing $1 \%$ BSA and $0.3 \%$ Triton X-100, in PBS for $1 \mathrm{hr}$, and then incubated with the primary antibodies in the blocking solution at $4^{\circ} \mathrm{C}$ overnight. Subsequently, sections were washed in PBS three times for $3 \mathrm{~min}$ and then incubated with the secondary antibodies in the blocking solution for $1.5 \mathrm{hr}$ at room temperature. The sections were washed again in PBS for 3 min three times and mounted in FluoSave (Calbiochem, La Jolla, CA). Confocal microscopy was performed using a Leica laser scanning microscope and TCS NT image software (Leica Microsystems Inc., Wetzlar, Germany).

For whole-mount immunostaining of the retina, the eyes were enucleated from mice fixed with $4 \%$ PFA in $0.1 \mathrm{M}$ PBS, $\mathrm{pH} 7.4$, by cardiac perfusion. The cornea, sclera, lens, and hyaloid vessels were removed to isolate the retina, which was then postfixed with $4 \%$ PFA in $0.1 \mathrm{M}$ PBS for $3 \mathrm{hr}$, then briefly microwaved. After washing with PBS several times, immunohistochemical staining essentially similar to the procedures on frozen sections was performed on whole-mount retinas.

The primary antibodies used were as follows: rabbit anti-Pax2 at 1:200 (Zymed, South San Francisco, CA); mouse anti-platelet-endothelial cell adhesion molecule-1 (PECAM-1) at 1:500 (BD PharMingen, San Jose, CA); mouse anti-CD140a (APA5) at 1:200 or 1:1000 (eBioscience, San Diego, CA); mouse anti- $\beta$-galactosidase at 1:500 (Promega, Madison, WI; Cappel, Durham, NC); mouse anti-glial fibrillary acidic protein (GFAP)-Cy3 conjugate at 1:200 or 1:1000 (Sigma, St. Louis, MO); mouse anti-glutamine synthetase (GS) at 1:500 (Chemicon, Temecula, CA); mouse anti-p27 ${ }^{\mathrm{Kip} 1}$ at 1:100 (BD Transduction Laboratories, San Jose, CA), mouse anti-syntaxin (HPC-1) at 1:2000 (Sigma); goat anti-Brn 3b at 1:200 (Santa Cruz Biotechnology, Santa Cruz, CA); mouse antiprotein kinase $\mathrm{C}(\mathrm{PKC})$ at 1:500 (Sigma); rabbit anti-calbindin at 1:1000 (Chemicon); mouse anti-rhodopsin at 1:10,000 (Sigma); biotinylatedpeanut agglutinin (PNA) at 1:200 (Vector Laboratories, Burlingame, $\mathrm{CA}$ ); rat anti-5'-bromo-2'-deoxyuridine (BrdU) at 1:10 (Oxford Biotechnology, Kidlington, UK); mouse anti-R-cadherin at 1:100 (BD Transduction Laboratories); mouse anti-cyclinD1 at 1:100 (Zymed); rabbit anti-CRALBP at 1:100 (a gift from John C. Saari, University of Washington, Seattle, WA).

The secondary antibodies; anti-rat IgG Alexa Fluor 488, 546, antirabbit IgG Alexa Fluor 488, 546, and anti-mouse IgG Alexa Fluor 488,
546 were all used at a dilution of 1:1000 (Molecular Probes, Eugene, OR). Nuclear staining was done with TO-PRO-3 iodide (Molecular Probes) at a dilution of 1:2000.

In situ hybridization. In situ hybridization was performed essentially as described (Ishibashi et al., 1995) with minor modifications. DigoxigeninUTP (Roche Molecular Biochemicals, Indianapolis, IN) was used for labeling of the probes (Tlx; GenBank accession number NM152229) according to the procedures described by the manufacturer's protocol (Roche).

Electron microscopic analyses. Eyes enucleated from embryos and postnatal mice were fixed in $2.5 \%$ glutaraldehyde in PBS overnight at $4^{\circ} \mathrm{C}$. Samples were washed in PBS for 10 min three times, dehydrated through a graded ethanol series, and then embedded in paraffin. Transverse sections $(5 \mu \mathrm{m})$ were prepared, mounted onto slides, and stained with hematoxylin-eosin. For electron microscopy, eyes were fixed with $2.5 \%$ glutaraldehyde and 2\% PFA in $0.1 \mathrm{~m}$ PBS, pH 7.4. Tissues were postfixed in phosphate-buffered $1 \%$ osmium tetroxide, $\mathrm{pH} 7.4$, dehydrated in an ascending ethanol series, and passed through propylene oxide. The blocks were embedded in EPON 812. Thin sections were stained in uranyl and lead salt solutions, and were examined by electron microscopy.

TUNEL assay. Apoptotic cell death was detected by using In Situ Cell Death Detection kit (Roche) according to the manufacturer's instructions. The number of apoptotic cells detected in the GCL, INL, and ONL was counted in at least five independent sections through the optic discs of enucleated eyes obtained between the ages of E16.5 and postnatal day 14 (P14) (at least three independent eyes were prepared from each age).

$\mathrm{BrdU}$ assay. A single intraperitoneal injection of BrdU $(100 \mathrm{mg} / \mathrm{kg}$ body weight in $0.9 \%$ sodium chloride solution; Sigma) was administered to the pregnant mice and pups at various developmental stages $2 \mathrm{hr}$ before killing. Frozen sections for the BrdU assay were prepared and subjected to the immunohistochemical analyses as described.

\section{Results}

\section{Spatial and temporal expression patterns of Tlx in the developing retina}

We first analyzed the expression pattern of Tlx in the retina during both embryonic and postnatal developmental periods. Taking advantage of the LacZ gene inserted into the Tlx genomic locus, we examined Tlx expression by detecting $\beta$-galactosidase ( $\beta$-gal) expression in heterozygous Tlx mice (Fig. 1).

$\beta$-gal expression was first detected on the innermost surface of the central retina at E11.5, and thereafter the area of $\beta$-gal expression extended toward the periphery (data not shown). $\beta$-gal expression appeared to be localized at the endfeet of RPCs in the NBL (Stuermer and Bastmeyer, 2000). From E13.5 onward, $\beta$-gal expression became localized uniformly in RPCs in the entire NBL and persisted there throughout nearly the entire period of retinal neurogenesis (Fig. $1 A-C$ ). In situ hybridization analyses of $T l x$ expression were consistent with $\beta$-gal patterns in that Tlx is prominently expressed by RPCs in the NBL (Fig. $1 A-F$ ). At E17.5 when astrocytes start to migrate onto the retina from the optic nerve, prominent $\beta$-gal expression was detected both within the optic nerve head and on the innermost surface covering the disc (Huxlin et al., 1992) (Fig. 1C,F). At early postnatal periods, $\beta$-gal expression became localized to the INL, where the Müller cell bodies reside (Fig. 1G,H) (data not shown) and persisted until the latest age examined ( 6 months) (data not shown). The $\beta$-gal pattern was characteristic of Müller cells (Fig. 1I), with fibers extending radially from the inner limiting membrane (ILM) to the outer limiting membrane (OLM) and cell bodies located in the INL. In situ hybridization confirmed the correlating expression of Tlx in the INL (Fig. $1 J$ ).

To further examine the identities of $\beta$-gal-positive retinal cell subtypes in the developing retina, cells on the inner surface of the retina were subjected to immunohistochemical studies (Fig. $2 \mathrm{~A}-$ $I)$. Platelet-derived growth factor receptor $\alpha$ (PDGFR $\alpha$ ) serves as 
a reliable marker of immature astrocytes migrating from the optic disc on the inner surface of retina at perinatal stages (supplemental material, available at www.jneurosci.org) (Mudhar et al., 1993; Fruttiger, 2002). Double immunohistochemical analyses at E17.5 revealed that PDGFR $\alpha$ expression was evident in $\beta$-gal-positive cells on the inner retinal surface and optic disc in $T l x$ heterozygous mice (Fig. 2A-C). Whole-mount retinas exhibited a cluster of $\beta$-gal and PDGFR $\alpha$ colabeled cells that were mostly centrally located around the optic disc, some of which emanated peripherally from the optic nerve on the inner retinal surface (Fig. $2 D-F)$. At P4, the $\beta$-gal and PDGFR $\alpha$ colabeled cells began to exhibit patterns characteristic of astrocyte networks (Fig. 2G-I), and at P7, when the network of astrocytes covered most of the inner retinal surface, $\beta$-gal expression was no longer detected there, whereas PDGFR $\alpha$ expression remained (data not shown), suggesting an early transient expression of Tlx by retinal astrocytes.

To confirm that the $\beta$-gal-positive cells that span fibers radially from the ILM to the OLM and have cell bodies in the INL are Müller cells, double immunohistochemical analyses of $\beta$-gal in relation to cellular retinal aldehyde-binding protein (CRALBP), a reliable molecular marker of Müller cells (Peterson et al., 2001) was performed (Fig. 2J-L). The expression pattern of $\beta$-gal in the mature retina was found to be essentially similar to that of CRALBP (Fig. $2 J-L$ ), indicating that Tlx expression is eventually confined to Müller cells in the mature retina.

These results indicate that Tlx is prominently expressed by RPCs in the NBL throughout nearly the entire period of retinal neurogenesis. After the generation of retinal progeny from the RPCs in the NBL, Tlx expression is confined to Müller cells and excluded from other retinal neural subtypes. Moreover, Tlx appears to be expressed by immature astrocytes at their early developmental periods when they migrate from the optic nerve and set up the characteristic cellular network on the inner surface of retina.

\section{Cell numbers in each nuclear layer are perturbed by the loss of $T l x$}

To address the issue of how Tlx contributes to the regulation of the neural organization of the developing retina, we first analyzed the morphological changes of Tlx KO retinas during the embryonic and postnatal retinal developmental period (Fig. 3). At the early embryonic stages, no apparent gross difference was observed between the retinas obtained from the littermates of wildtype and Tlx KO homozygotes (data not shown). At P0, by which time the GCL is established, this layer appeared to contain an increased number of cells ( $1.28 \pm 0.09$-fold difference; mean \pm $\mathrm{SD} ; n=8$ independent eyes), whereas the NBL had a decrease in cell number $(0.74 \pm 0.05$-fold difference; $n=8$ in Tlx KO retinas compared with wild-type) (Fig. $3 A, B, I$ ). At P7 when the INL and ONL are well established as distinct layers, the cellularity of the
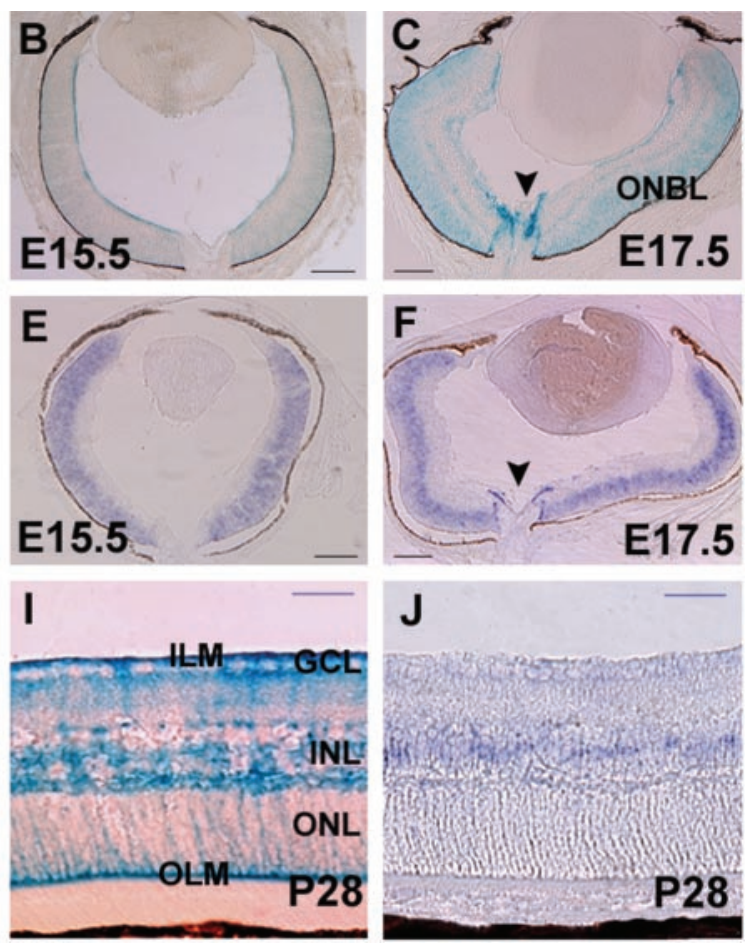

Figure 1. Spatial and temporal expression patterns of Tlx in the developing retina. $\beta$-gal patterns at $\mathrm{E} 13.5(A), \mathrm{E} 15.5(B), \mathrm{E} 17.5$ C), P14 (G), and P28 $(H, I)$, and Tlx expression detected by in situ hybridization analyses at E13.5 (D), E15.5 (E), E17.5 ( F), and P28

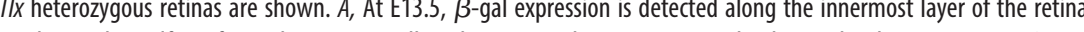
characteristic morphologies of Müller cells. J, In situ hybridization analyses showed that Tlx was mainly detected in the central region of the INL. ONBL, Outer neuroblastic layer. Arrowhead, Optic disc. Scale bars: $A-H, 160 \mu \mathrm{m} ; \mathrm{I}, \mathrm{J}, 40 \mu \mathrm{m}$.

INL was increased ( $1.29 \pm 0.08$-fold difference; $n=8)$, whereas that of the ONL was decreased $(0.71 \pm 0.05$-fold difference; $n=$ 8 ) in Tlx KO retinas compared with wild-type (Fig. 3C,D,I). By P14, the initially expanded GCL and INL became progressively hypoplastic and the number of cells comprising each layer was reduced in Tlx KO retinas (Fig. 3E,F,I). At P28, the overall thickness of the $T l x \mathrm{KO}$ retina was strikingly reduced apparently because of a global decrease in cell number in all layers (Fig. 3G-I).

We next asked if the specification of each retinal cell type identity might be perturbed by the loss of Tlx (supplemental material, available at www.jneurosci.org). We examined Tlx KO retinas at 1 month after birth when the identities of distinct retinal cell types are well established. Molecular markers were used that have been shown to reliably identify individual neuronal subtypes in the retina (Inoue et al., 2001): Brn3b for RGCs, HPC-1 for amacrine cells, PKC for bipolar cells, calbindin for horizontal cells, rhodopsin (Ret P-1) for rod photoreceptors, and PNA for cone photoreceptors. We found that in the KO retina, the markers for all of these retinal neuronal subtypes were detected appropriately in each layer, albeit a reduction in cell number (supplemental material, available at www.jneurosci.org).

These results indicate that each retinal neuronal subtype identity is specified appropriately, even in the absence of Tlx and, furthermore, there appears to be no specific loss of a particular retinal neuronal subtype in Tlx $\mathrm{KO}$ retinas. However, retinal cells that are generated from the NBL at earlier stages of retinal neurogenesis, in the GCL and INL, appeared to be initially expanded 

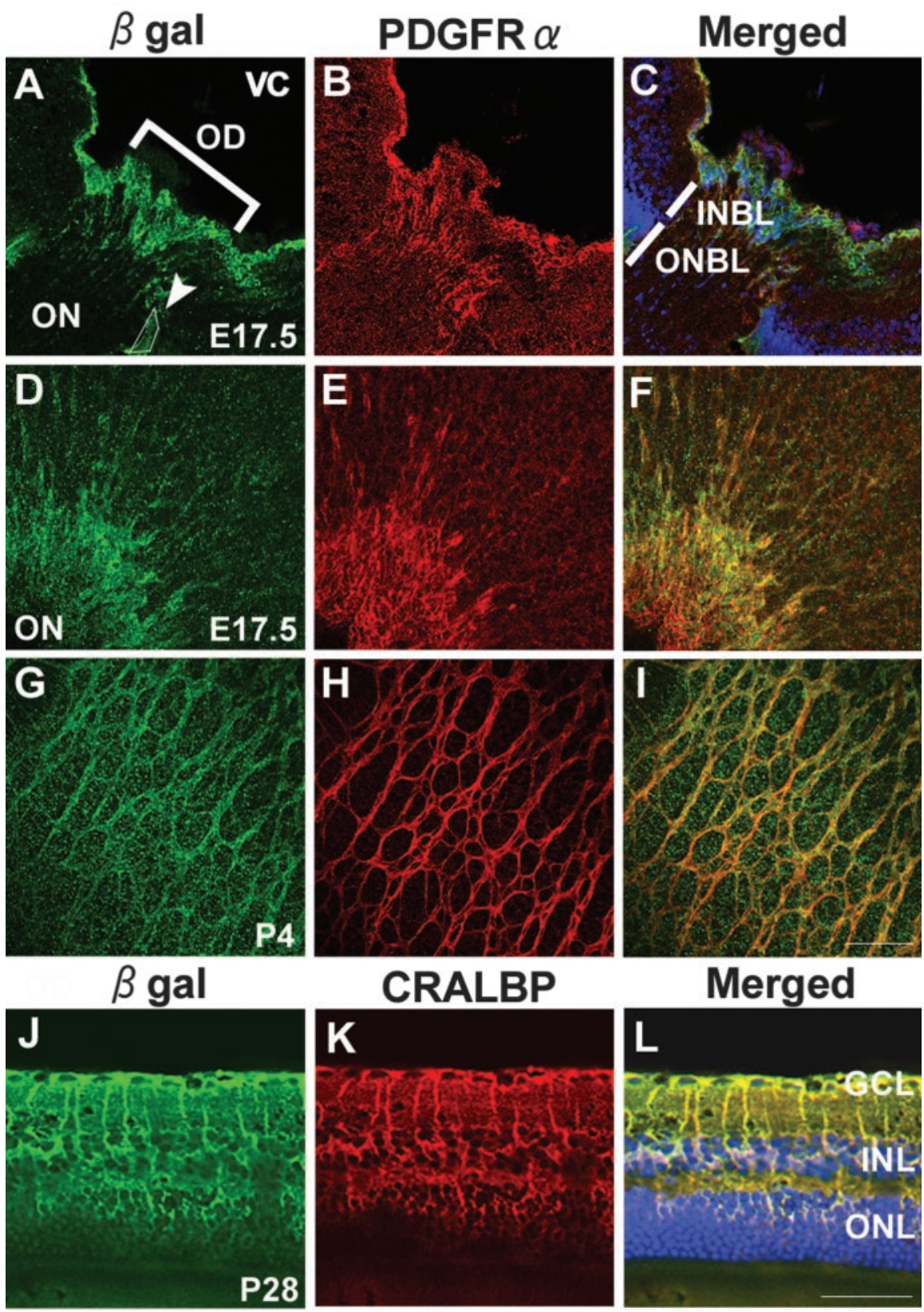

Figure 2. Tlx expression by Müller cells and immature astrocytes. $A-I$, Immunohistochemical analyses of $\beta$-gal expression in T/x heterozygous retinas using antibodies against $\beta$-gal (green) in relation to PDGFR $\alpha$ (red), an early marker of astrocytes. $A-C$, Cross sections of E17.5 retina through the optic disc were shown. AtE17.5, $\beta$-gal and PDGFR $\alpha$ colabeled cells were detected inside the optic disc and over the inner surface of the retina. Note that some of the colabeled cells were localized in the focal region of retina-optic nerve boundary ( $A$, arrowhead) where astrocyte precursor cells are suggested to be localized (Chu et al., 2001). Cell nuclei in C were labeled with T0-PRO-3 iodide (blue). D-F, Whole-mount preparations of E17.5 retina adjacent to the optic disc Whole-mount immunostaining showed that $\beta$-gal and PDGFR $\alpha$ colabeled cells were spreading over the inner retinal surface tangentially from the optic disc to the periphery. $G-I$, Whole-mount preparations of $\mathrm{P} 4$ retina adjacent to the optic disc were shown. At P4, $\beta$-gal and PDGFR $\alpha$ colabeled cells exhibited a pattern characteristic of astrocyte network. J-L, Immunohistochemical analyses of $\beta$-gal expression in 1-month-old T/x heterozygous retina using antibodies against $\beta$-gal (green) in relation to CRALBP (red), a marker for Müller cells. Most of the $\beta$-gal stainings were colocalized with CRALBP, indicating that Tlx expression is confined to Müller cells in 1-month-old retina. Cell nuclei were labeled with TO-PRO-3 iodide (blue). OD, Optic disc; ON, optic nerve; VC, vitreous cavity; INBL, inner neuroblastic layer; ONBL, outer neuroblastic layer. Scale bars: (in I) $A-I, 80 \mu \mathrm{m}$; (in L) $J-L, 40 \mu \mathrm{m}$.

in number, whereas retinal cells generated at later stages of retinal neurogenesis, in the ONL, appeared to be initially reduced in number in Tlx KO retinas. In addition, the number of RPCs located in the NBL appeared to be less when the cohort of post- mitotic cell populations is detected at early postnatal stages in the GCL.

Changes in mitotic status of retinal progenitor cells in $T l x$ KOs

Perturbation in the control of cell number can result from increased-decreased apoptosis and/or changes in the mitotic status (whether to maintain a proliferative state or to differentiate) of progenitor cells at the time when each retinal progeny is generated.

We first examined whether any changes in the rate of apoptosis might underlie the dysregulation of cell number in the Tlx KO retinas (Fig. 4). At the stage when the GCL became distinct, an increase (approximately fourfold) in the extent of apoptosis in the GCL was observed in Tlx $\mathrm{KO}$ retinas compared with wildtype and persisted thereafter (Fig. $4 A, B, E)$. At $\mathrm{P} 7$ when the formation of the three distinct nuclear layers is nearly completed, more apoptotic cells (approximately threefold increase) were observed in the INL of Tlx KO retinas than those of wild-type (Fig. 4C-E). In contrast to the GCL and INL, however, the ONL did not exhibit a marked increase in the number of apoptotic cells in $T l x \mathrm{KO}$ retinas (Fig. 4E).

We next examined if there is any change in the status of progenitor cell proliferation in the NBL (Fig. 5). To monitor the number of mitotic cells, progenitor cells in the S-phase of the cell cycle were labeled in vivo by a pulse of BrdU into pregnant mice at E15.5 and E17.5 (Fig. $5 A-D)$. At E15.5, the proportion of BrdUlabeled cells in the outer NBL of Tlx KO retinas $(12.7 \pm 1.3 \%)$ was similar to wildtype $(12.7 \pm 1.6 \%)$ (Fig. $5 A, B, M)$. When later stage embryos were injected, the proportion of BrdU-positive cells in Tlx $\mathrm{KO}$ retinas $(8.2 \pm 1.5 \%)$ declined compared with wild-type $(11.1 \pm 1.2 \%)$ (Fig. $5 C, D, M)$. This decrease in the proportion of mitotic cells suggested that the expression of cell cycle-related molecules was affected (Dyer and Cepko, 2001b). When we compared the number of cells expressing cyclin D1, a critical component in the cell cycle machinery for re-entry into the next cell cycle (Fig. $5 E-H, M$ ), a marked reduction in the proportion of cyclin D1positive cells in Tlx KO retina (19.7 \pm $1.6 \%$ at $\mathrm{E} 15.5 ; 14.6 \pm 1.1 \%$ at $\mathrm{E} 17.5)$, compared with wild-type $(30.4 \pm 1.8 \%$ at E15.5; $19.3 \pm 0.9 \%$ at E17.5) was observed. In contrast, the proportion of cells expressing $\mathrm{p} 27^{\mathrm{Kip} 1}$, a Cip-Kip family of cyclin-dependent kinase inhibitor (CDKI) that blocks cell cycle reentry, was markedly increased in the inner NBL of Tlx KO retinas $(13.2 \pm 1.1 \%$ at 


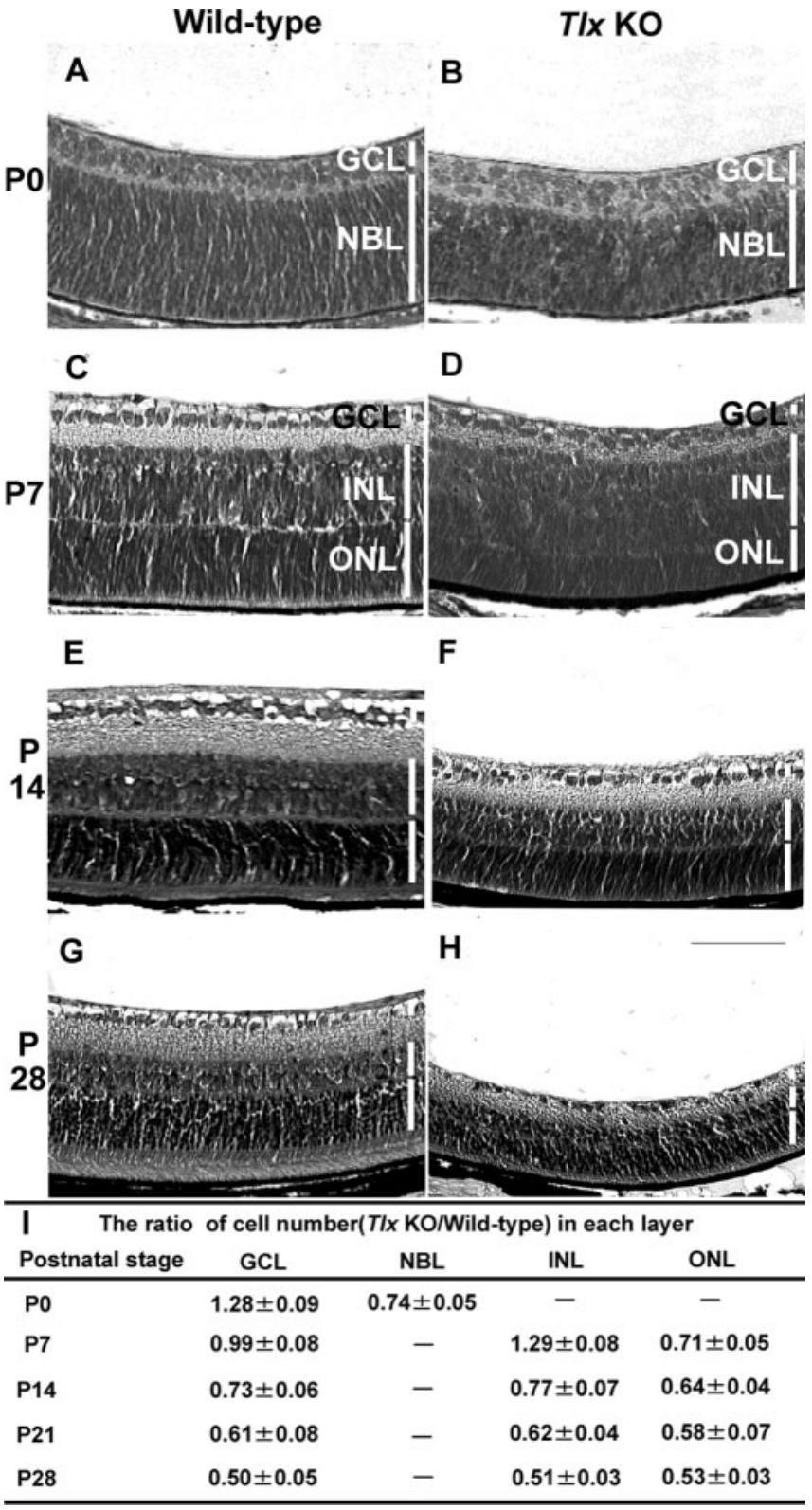

Figure 3. Retinal cell number perturbation during the developmental stages of $T / x$ KO retina. $A-H$, Hematoxylin- eosin staining of wild-type $(A, C, E, G)$ and $T / x K O(B, D, F, H)$ retinal cross sections obtained at $\mathrm{PO}(A, B), \mathrm{P} 7(C, D), \mathrm{P} 14(E, F)$, and P28 $(G, H) . A-D, A t \mathrm{PO}$, the $G C L$ of $T / x$ KO retinas $(B)$ was expanded, whereas the NBL was narrow in width, compared with wild-type retinas $(A)$. C, D, At P7, the INL of T/x KO retinas was expanded whereas the 0 NL was decreased, compared with wild-type retinas. E, F, At P14 in T/x KO retinas, the thickness of the INL was reduced, whereas the ONL became thinner with the poor development of outer segments. Furthermore, both the density of cells located at the $\mathrm{GCL}$ and the thickness of the inner plexiform layer was reduced. $G, H$, The reduction in thickness of each nuclear layer remained, and the overall thickness of the $\mathrm{K} 0$ mouse retina became approximately half of the wild-type retina at P28. I, Quantitative analyses of fold changes of retinal cell number located at each layer. Each data point represents values (mean values \pm SD) obtained from $>20$ independent sections derived from more than eight retinas of either wild-type or T/x KO mice. Scale bar, $80 \mu \mathrm{m}$.

E15.5; $12.6 \pm 0.7 \%$ at E17.5) compared with wild-type $(3.7 \pm$ $0.5 \%$ at E15.5; $3.4 \pm 0.4 \%)$ at E17.5 (Fig. 5I-M).

Müller cell identities in $T l x \mathrm{KO}$ retinas

After its expression in RPCs, Tlx expression is eventually confined to Müller cells at the later stages of retinal development. When we analyzed the expression of glutamine synthetase (GS), a

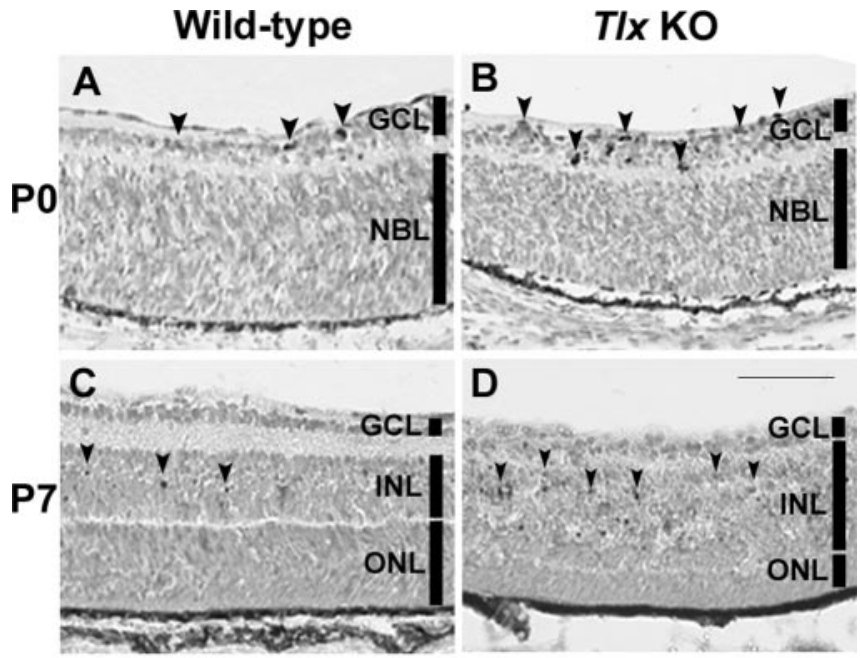

E

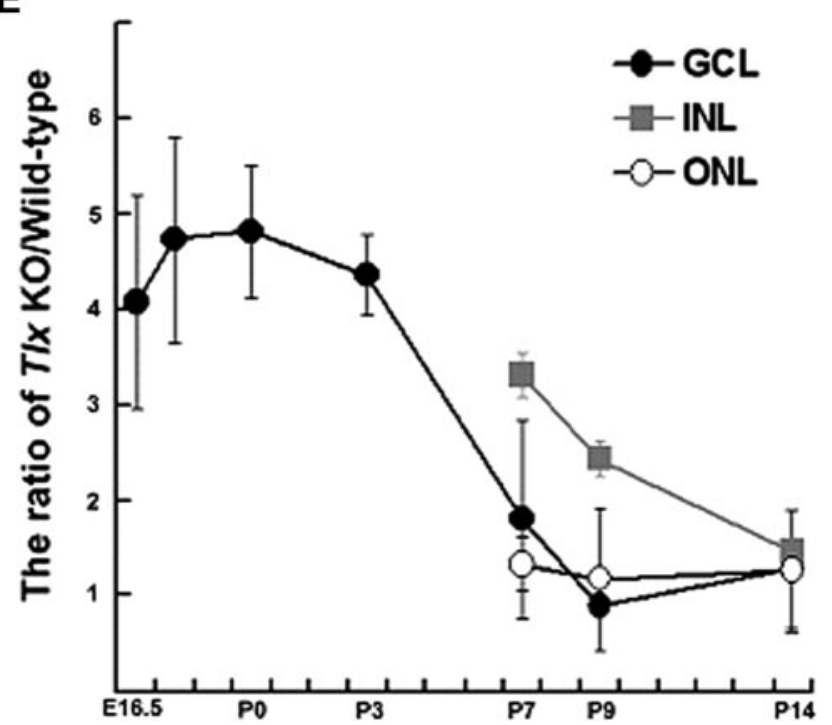

Figure 4. Apoptosis in $T / x$ KO Retinas. $A-D$, TUNEL staining of wild-type $(A, P 0 ; C, P 7)$ and $T / x$ $K 0$ retinas $(B, P 0 ; D, P 7) . A, B, A t P 0$, more numbers of TUNEL-positive cells (arrowheads) were observed in the expanded GCL of $T / x K 0$ retinas, compared with wild-type retinas. $C, D, A t P 7$, the number of apoptotic cells (arrowheads) was increased in the INL of TIx KO retinas, compared with wild-type. E, Quantitative data showing the time course of fold changes of the number of TUNEL-positive cells obtained from T/x KO retinas and wild type. Data points represent the values (mean values $\pm S D$ ) from $>10$ sections derived from at least three independent samples. In T/x KO retinas, marked increases in apoptotic cell death were first detected in the GCL, followed by the INL. There were only a slight increases in apoptosis detected in the $0 N L$ in T/x KO retinas compared with wild-type retinas.

molecular marker of Müller cells, in Tlx KO retinas, GS expression was detected in a pattern similar to wild-type (supplemental material, available at www.jneurosci.org), suggesting that the Müller cell identity had been acquired even in the absence of Tlx. When we analyzed GFAP, normally a molecular marker for differentiated astrocytes, but one that also detects Müller cells under reactive conditions (Ekstrom et al., 1988), GFAP was observed within the retina in a pattern similar to Müller cells (supplemental material, available at www.jneurosci.org). In addition, over the inner surface of the retina, where astrocytes and processes of Müller cells are located, only weak expression of GFAP was detected in Tlx KO retinas compared with wild-type (supplemental material, available at www.jneurosci.org), suggesting that there might be a reduction in the number of astrocytes and that the development of Müller cells might be perturbed by the loss of Tlx. 


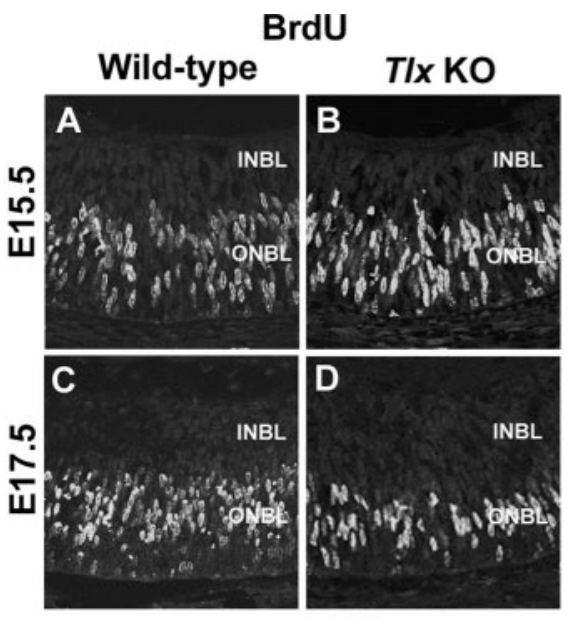

cyclinD1
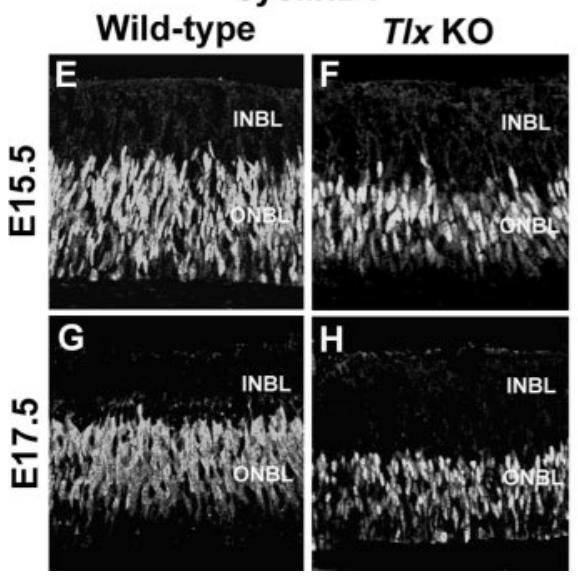

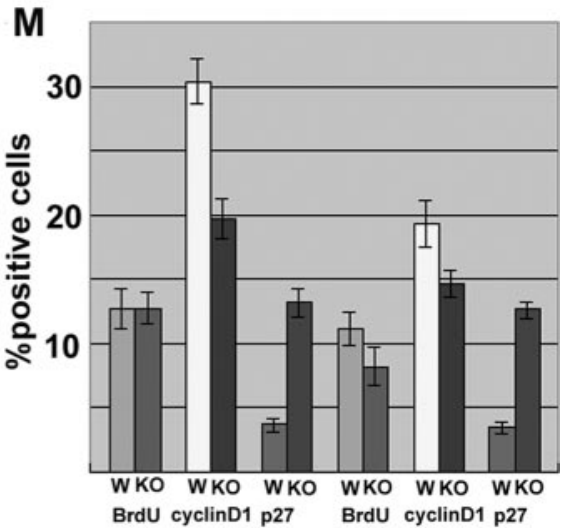

E15.5

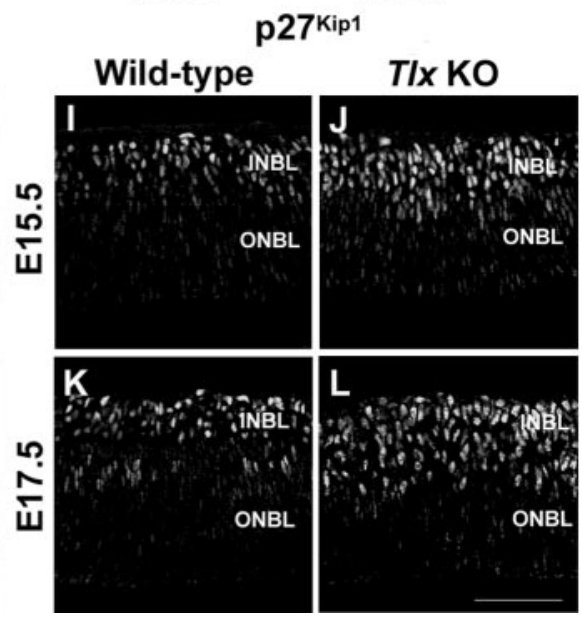

Impaired astrocyte migration and network formation in $T l x \mathrm{KO}$ retinas Our results show that Tlx is transiently expressed by retinal astrocytes at the time when these cells migrate tangentially from the optic nerve into the retina and form a characteristic glial network on the inner surface of retina, raising the possibility that Tlx is involved in astrocyte differentiation.

We thus focused on the aspect of astrocyte development involving network formation on the inner retinal surface (Fig. 7). In the wild-type, the characteristic intricate cellular networks progressively cover the inner retinal surface postnatally. By P4, many astrocytes with prominent PDGFR $\alpha$ and GFAP expression were located on the inner retinal surface. In contrast, in the Tlx KO retina, only a few $\operatorname{PDGFR} \alpha$-positive and GFAP-positive astrocytes were detected centrally over the optic disc (data not shown). By P7, astrocytes in wild-type retinas appeared to have acquired their mature phenotypes and exhibited a honeycomb network pattern covering most of the retinal surface (Fig. $7 A-C)$. In Tlx $\mathrm{KO}$ retinas, however, the distribution of astrocytes that had migrated to the retina was mostly confined centrally, emanating within a range of only $50 \%$ of the total central-peripheral distance, with the peripheral region negative for astrocytes (Fig. $7 D-F$ ) (data not shown). In addition, these centrally located astrocytes never formed the intricate cellular networks that interconnect their processes to give a characteristic dendritic pattern (Fig. $7 D-F$ ). These incomplete patterns of astrocyte networks in Tlx KO retinas remained essentially similar even at adult stages (data not shown). In contrast, in adult wild-type retinas, the network of astrocytes developed to exhibit a

To further examine if there is any defect in Müller cell development and maintenance by the loss of Tlx, we performed electron microscopic (EM) analyses on Tlx KO retinas (Fig. 6). The ILM is comprised of the processes of Müller cells. When we analyzed INL at E17.5, there was virtually no structural difference between wild-type and Tlx $\mathrm{KO}$ retinas (data not shown). At P4, in wild-type retinas, the ILM consisted of thick solid Müller cell processes and was covered by the basement membrane (Fig. $6 A, B$ ). In contrast, in $T l x \mathrm{KO}$ retinas at $\mathrm{P} 4$, the ILM was disorganized, and Müller cell processes were remarkably reduced in thickness. Disruption of Müller cell processes was occasionally observed, resulting in the exposure of neuronal axons to the basement membrane near the vitreous body (Fig. 6C). At adult stages, wild-type retinas had ILM with thick layers of cell processes and neuronal axons, together with well developed vessels (Fig. 6D), whereas Tlx KO retinas had only ILM with thin processes of Müller cells and atrophic nerve fiber layers (Fig. 6E). Thus, these observations indicate that Tlx KO retinas show a defect in the ultrastructure of Müller cells, especially in the inner side of the retina. characteristic shaft formation over the inner surface, emanating from the optic disc (data not shown).

The vessels on the inner surface of the retina are tightly associated with the astrocyte networks (Provis, 2001; Fruttiger, 2002), which prompted us to examine whether there is any defect in the formation of vessels in Tlx $\mathrm{KO}$ retinas. At P7, in wild-type retinas, the formation of the vessel network shows a spatial correlation with the pattern of the astrocyte network (Fig. 7G). In Tlx KO retinas, no vessel formation was detected over most of the inner retinal surface where no astrocyte migration is detected. Furthermore, even in the central regions where a partial astrocyte network formation is detected, little, if any, vessel formation was detected in Tlx KO retinas (Fig. 7D-F,H). Moreover, in the adult, no prominent retinal vascular formation was observed in the $T l x$ $\mathrm{KO}$, as reported previously (Young et al., 2002) (data not shown). The lack of vasculogenesis even in the regions where astrocytes are present prompted us to examine if astrocytes in Tlx $\mathrm{KO}$ retinas express vascular endothelial growth factor (VEGF) (Provis, 2001) and R-cadherin (Dorrell et al., 2002), two critical factors 
for vasculogenesis. Double immunostaining studies using antibodies against PDGFR $\alpha$ in combination with antibodies against either VEGF or R-cadherin revealed that both VEGF and R-cadherin were expressed by wild-type retinal astrocytes (data not shown) (Fig. 7I-K). In contrast, in Tlx KO retinas, VEGF but not $\mathrm{R}$-cadherin expression was observed in astrocytes (data not shown) (Fig. $7 L-N)$.

\section{Changes in the mitotic status of} premature astrocytes by the loss of Tlx Our finding that Tlx is critical for the control of the number of retinal progeny generated from RPCs in the NBL led us to examine whether the mitotic activity of astrocyte precursor cells is also perturbed by the loss of Tlx (Fig. 8).

To monitor the extent of astrocyte generation, we used Pax2 to define cells in the astrocyte lineage (Fig. 8A-L) (Mi and Barres, 1999). We analyzed the number of mitotic astrocyte precursor cells $2 \mathrm{hr}$ after a pulse of BrdU. At E17.5 in wild-type retinas, there was a large population of Pax2positive and BrdU-positive cells in the optic nerve and on the inner retinal surface (Fig. 8A-C). In contrast, there were very few Pax2-positive and BrdU-positive cells in the optic nerve and retinas of Tlx $\mathrm{KO}$ mice (Fig. 8D-F). At P0, whereas increased numbers of Pax 2 and BrdU colabeled cells were detected in wild-type retinas (Fig. 8G-I), only a few Pax2-positive and BrdU-positive cells appeared in the optic nerve of Tlx $\mathrm{KO}$ mice (Fig. $8 J-L$ ). The proportion of BrdU-labeled cells within the Pax2-positive astrocytes were reduced in Tlx KO mice $(0.13 \pm 0.02 \%)$, compared with wild-type $(0.63 \pm 0.11 \%)$ at P0. At P3 and thereafter, the number of Pax2 and BrdU colabeled cells were decreased in both wild-type and Tlx $\mathrm{KO}$ mice (data not shown). When we analyzed the expression of cyclin D1 together with PDGFR $\alpha$ (Fig. $8 M-X$ ), there were very few PDGFR $\alpha$ - and cyclin D1-positive astrocytes detected in the retinas and optic disc of Tlx KO mice, compared with wildtype. Thus, these results suggest that Tlx is required for the proper mitotic regulation in astrocyte precursor cells to generate appropriate numbers of retinal astrocytes in the developing eye.

\section{Discussion}

Our studies provide evidence that Tlx is expressed by RPCs and is critical for the generation of the appropriate numbers of retinal cell subtypes in each nuclear layer. Tlx expression is confined to Müller cells in mature retinas and appears to control Müller cell development. Moreover, the
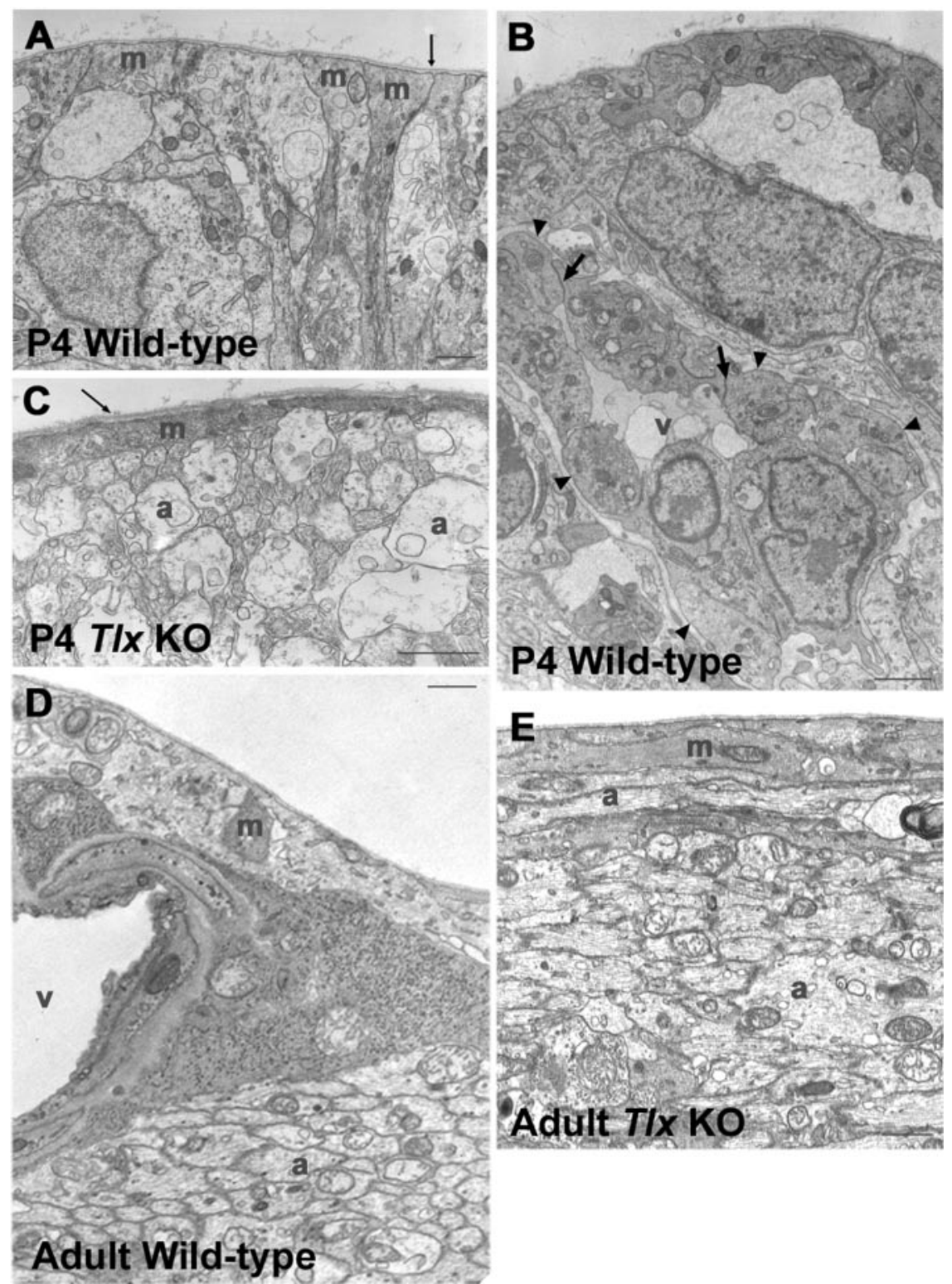

Figure 6. Müller cell development in T/x KO retinas. Electron microscopic analyses of $\mathrm{P} 4$ wild-type $(A, B), \mathrm{P} 4 \mathrm{Tl} \times \mathrm{KO}(C)$, adult wild-type (D), and adult TIX KO $(E)$ retinas. $A, B$, In P4 wild-type retinas, Müller cell processes $(A, \mathrm{~m})$ were tightly adhered to ILM (thin arrow). The invasion of vascular endothelial cells ( $v$ ) was observed ( $B$, arrowheads) along the ILM in wild-type retinas. Junctional structures between the vascular endothelial cells are indicated by thick arrows in $B$. $C$, In contrast, in P4 KO retinas, Müller cell processes ( $\mathrm{m}$ ) were remarkably thinner, and axonal bundles (a) were located closer to the basement membrane of ILM, compared with the wild-type. The basement membrane of ILM is indicated by thin arrows in $A$ and C. D, In adult wild-type retinas, blood vessels ( $v$ ) and thick Müller cell processes $(\mathrm{m}$ ) were seen in ILM, and axonal bundles (a) were detected beneath the Müller cell processes. E, However, in TIX KO retinas, Müller cell processes $(\mathrm{m})$ within the ILM were much thinner than those of wild-type, so that axonal bundles (a) were situated closer to the vitreous body. Scale bars, $1 \mu \mathrm{m}$.

expression of Tlx by immature astrocytes is critical for the generation of retinal astrocytes that cover the retinal surface and for the acquisition of their mature phenotype, characterized by intricate network formation and induction of vasculogenesis.

Figure 7. Impaired astrocyte network formation and vasculogenesis. $A-F$, Whole-mount immunohistochemical analyses of astrocyte network formation at P7 using antibodies against PDGFR $\alpha$ (green), one of the earliest marker for retinal astrocytes, and GFAP (red), a marker of differentiated retinal astrocytes. $A-C$, Wild-type retinas exhibited the characteristic honeycomb pattern of cellular network formed by PDGFR $\alpha$-positive and GFAP-positive astrocytes over most of the retinal surface. $D$ - $F$, In contrast, fewer PDGFR $\alpha$-positive and GFAP-positive astrocytes were detected over the surface of $T / x \mathrm{KO}$ retinas and never formed a dendritic network. $G, H$, Immunohistochemical analyses of vasculogenesis at P7 using PECAM-1 (green), an antibody against vascular 
P7 PDGFR $\alpha$
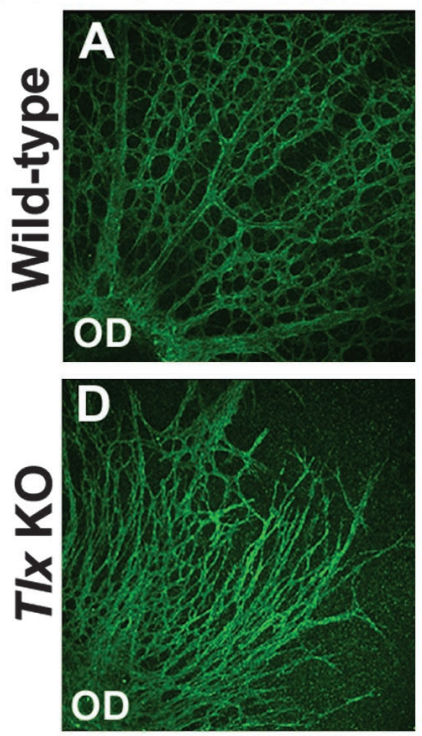

Wild-type
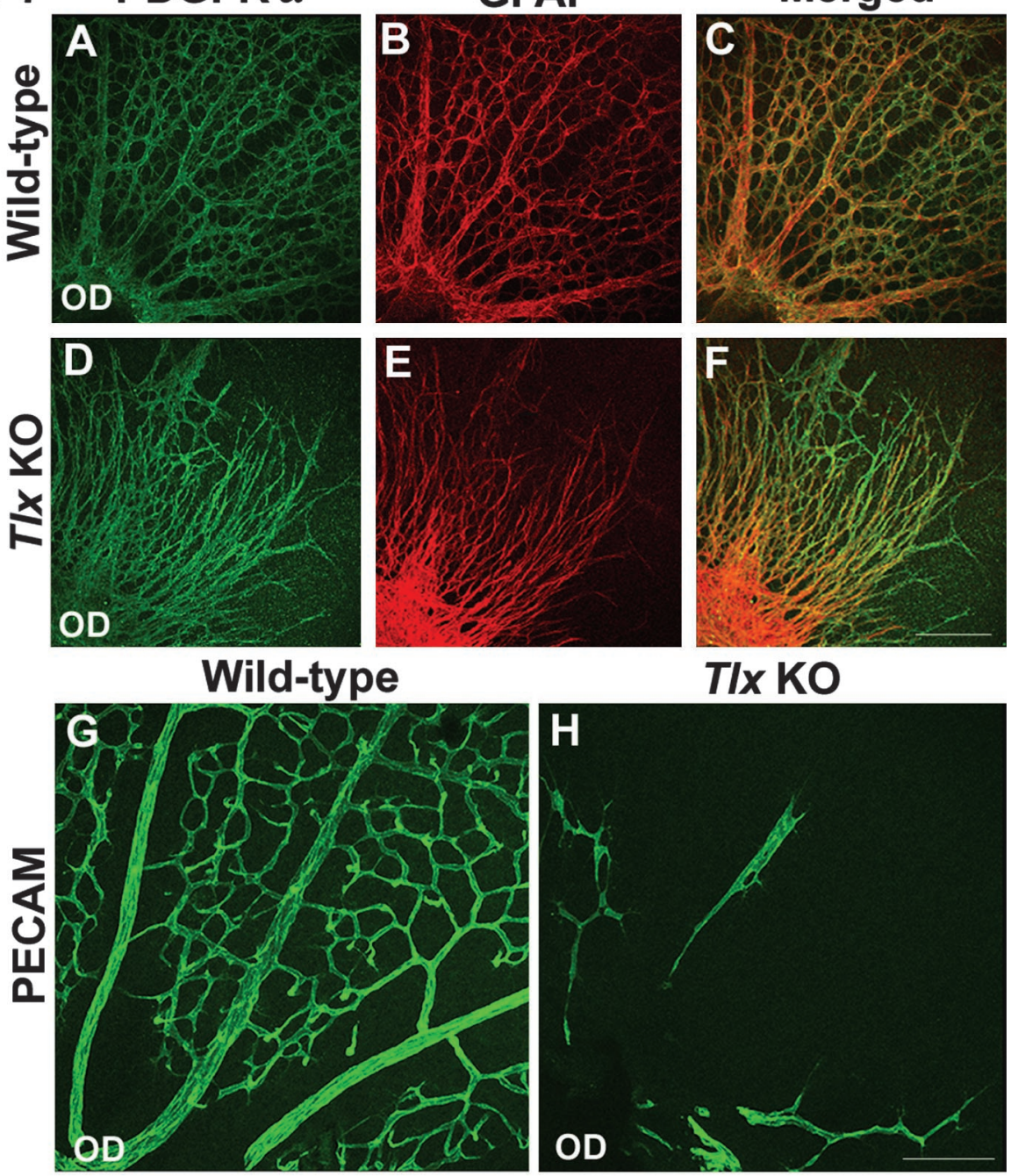

TIX KO
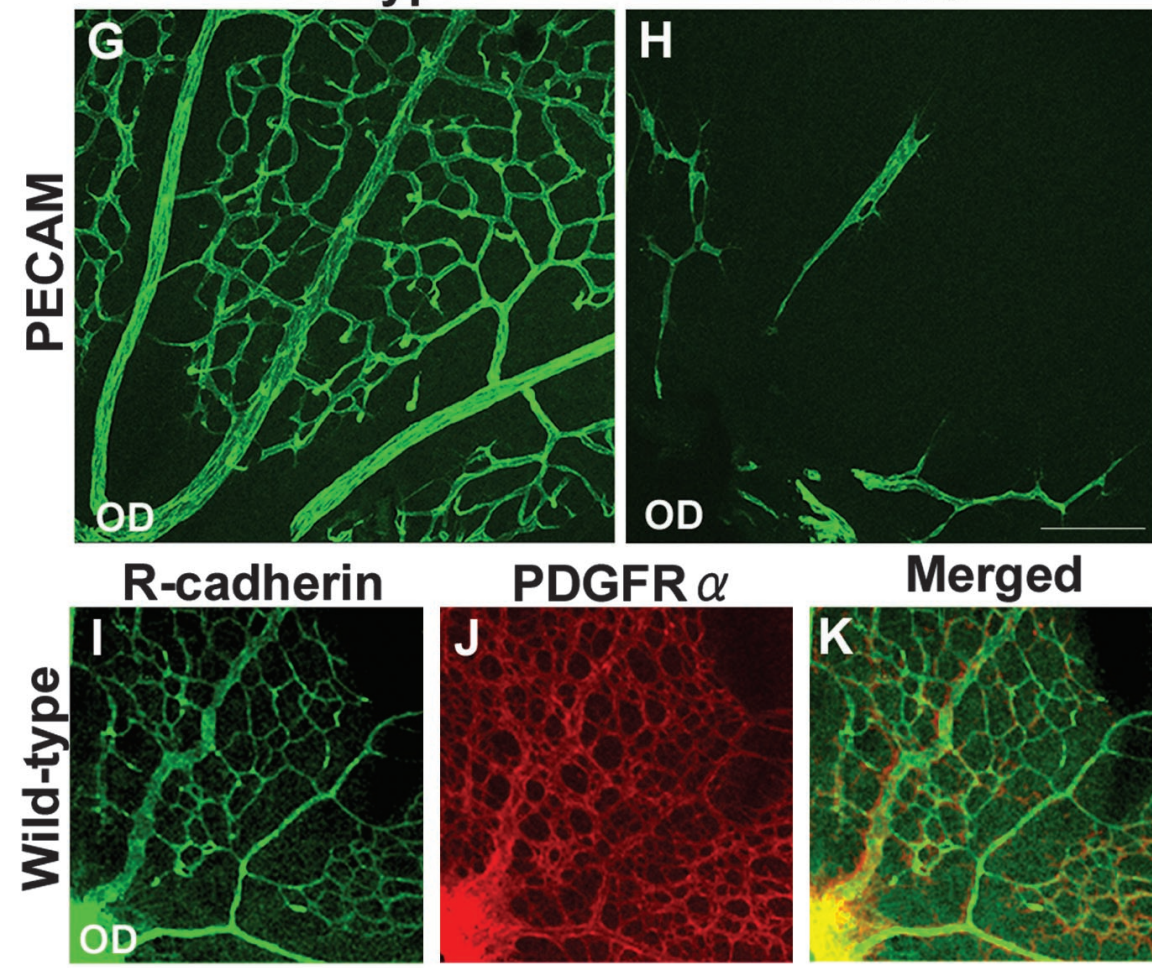

PDGFR $\alpha$
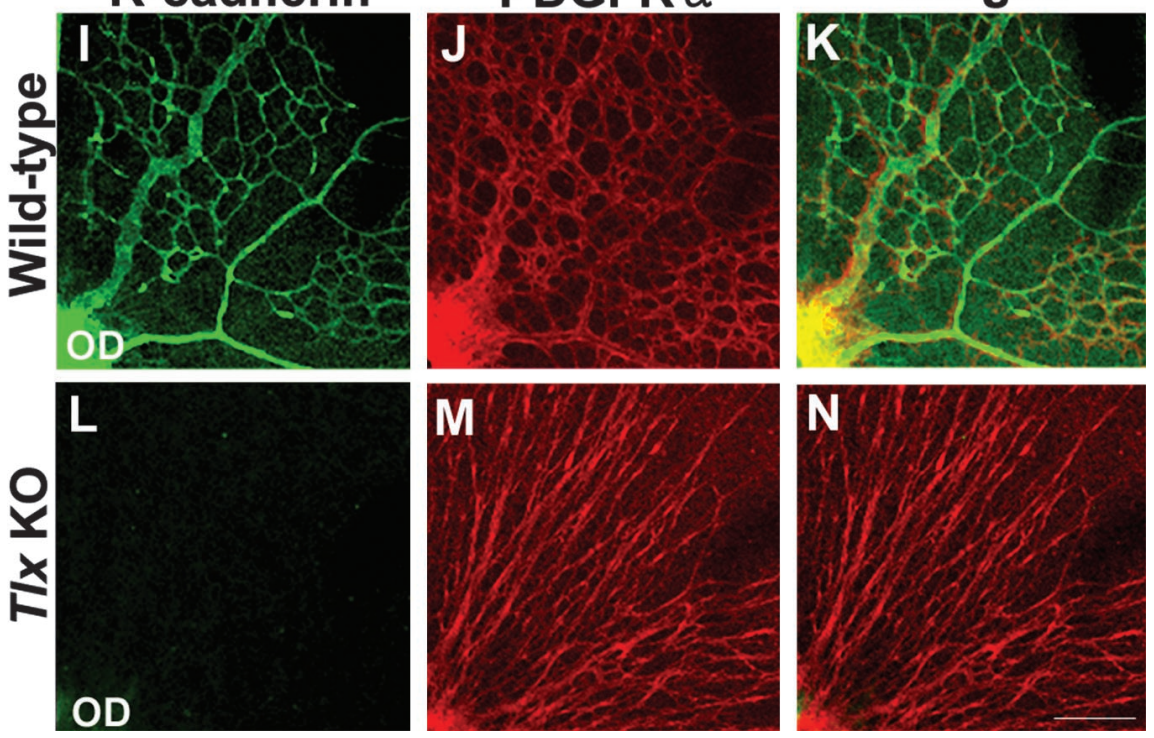

endothelial cells. At P7, well formed vessels were detected in wild-type retinas, whereas the vessel network was never formed in $T / x \mathrm{KO}$ retinas. Even in the adult, no vascular formation was detected in $T / x$ KO retinas (data not shown). I-N, Whole-mount immunohistochemical analyses of astrocyte network formation at P7 using antibodies against R-cadherin (green) and PDGFR $\alpha$ (red). Wild-type retinas (I-K) showed intricate astrocyte network formation, revealed by PDGFR $\alpha$ and R-cadherin expressions. In contrast, TIx KO retinas $(L-N)$ showed impaired network formation, as revealed by PDGFR $\alpha$. No expression of R-cadherin was detected. Scale bars, $160 \mu \mathrm{m}$.
Control of the number of retinal cell subtypes in each nuclear layer

The numbers of distinct retinal cell populations appear to be determined by the intimate regulation of proliferation, differentiation, and cell death. Previous studies identified several cell-intrinsic and extrinsic cues that are involved in cell proliferation and differentiation in the retina, however, the mechanism by which this switch between proliferation and differentiation is controlled in RPCs remains widely obscure (Marquardt et al., 2001; Marquardt and Gruss, 2002). Cyclins and CDKI, especially cyclinD1 and p $27^{\mathrm{Kip} 1}$, were shown to play major roles in the cell cycle regulation of RPCs (Levine et al., 2000; Dyer and Cepko, 2001a,b). A lack of these molecules results in the characteristic pattern of retinal degeneration (Fantl et al., 1995; Sicinski et al., 1995; Ma et al., 1998; Levine et al., 2000; Dyer and Cepko, 2001a,b). Studies using mouse genetics have provided evidence that interactions between the cell cycle-related proteins and homeodomain proteins are critical for setting up the proper number of distinct retinal cell types. For example, the activities of p $27^{\text {Kip } 1}$ in the RPCs appears to be regulated by Chx10 and Six6. The loss of either Chx10 or Six6 was shown in vivo to result in the reduction of RPC proliferation and eventual reduced numbers of retinal cell progenies ( $\mathrm{Li}$ et al., 2002; Green et al. 2003). Another homeodomain protein, Prox1, which is expressed by a subset of RPCs, is shown to be involved in the regulation of cell numbers by apparently upregulating $\mathrm{p} 27^{\mathrm{Kip} 1}$ and $\mathrm{p} 57^{\mathrm{Kip} 2}$ expressions (Dyer et al., 2003). In addition to homeodomain proteins, recent studies suggest that nuclear receptors are involved in the control of retinal neural subtype cell numbers. PNR was shown to suppress the proliferation of cone photoreceptor progenitor cells (Yanagi et al., 2002), and $\operatorname{ROR} \beta$ was shown to regulate the number of RPCs in accordance with Chx10 (Chow et al., 1998). Docosahexaenoic acid, a ligand of $\operatorname{RXR} \beta$, appears to upregulate p2 $7^{\text {Kip1 }}$ in vitro and is necessary for photoreceptor progenitors to start differentiation (Insua et al., 2003). However, the intricate cell-intrinsic networks mediated by nuclear receptors that might contribute to the control of generation of appropriate numbers of each retinal cell type remained to be elucidated in vivo.

In this study, the lack of Tlx affects the initial cell number in each nuclear layer depending on the time of cell generation. A decreased cell number in the superficial layers generated at later stages of develop- 

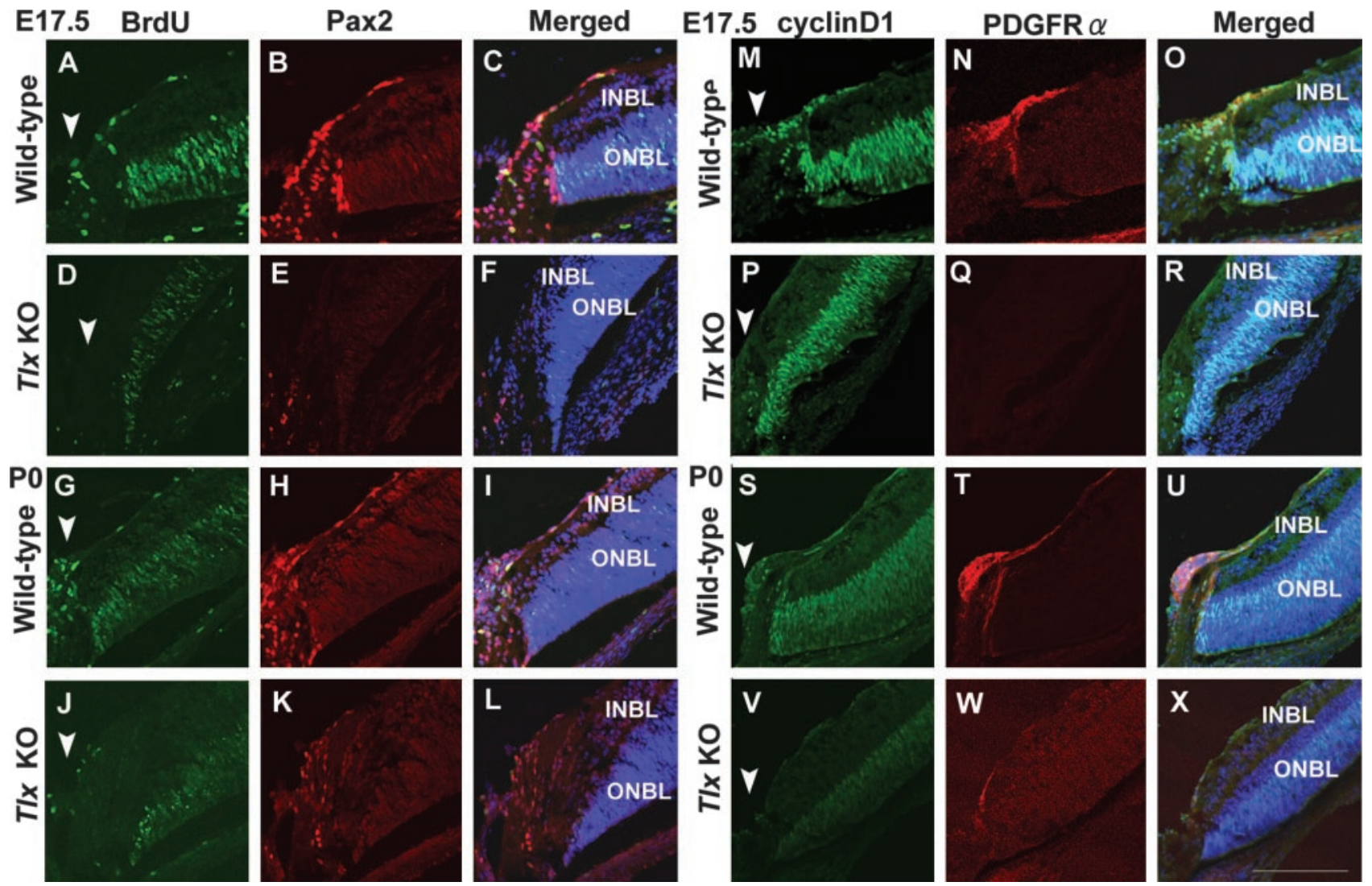

Figure 8. Changes in the mitotic status of immature astrocytes by the loss of Tlx. $A-L$, BrdU-labeling analyses of the mitotic status of immature retinal astrocytes at perinatal stages. At E17.5 in wild-type retinas $(A-C$, most of the Pax2-positive (red) astrocytes in the optic nerve and over the inner surface of retina were positive for the BrdU (green) labeling. In contrast, only a few Pax2-positive cells were detected in T/x KO optic nerves at E17.5 (D-F) and were not labeled by BrdU. In wild-type retinas $(G-I)$ at P0, the number of Pax2 and BrdU colabeled cells were increased compared with E17.5 $(A-C)$, whereas in T/x KO retinas $(J-L)$ at $P 0$, only a few cells were positive for the expressions of BrdU and Pax2 similar to E17.5 (D-F).M-X, Immunohistochemical analyses of cyclin D1 expression in the retinal astrocytes at perinatal stages. Immunostaining of wild-type retinas showed that most PDGFR $\alpha$-positive (red) astrocytes around the optic disc were positive for the expression of cyclin D1 (green) (M-0). The number of cyclin D1-positive and PDGFR $\alpha$-positive astrocytes inside the optic nerve head was subsequently decreased in wild-type retinas at P0 $(S-U)$. In contrast, only a few PDGFR $\alpha$-positive astrocytes were detected over the optic disc, and cyclin D1 expression in these astrocytes was not detectable in Tlx KO retinas (P-R, V-X, data not shown). Blue staining in merged sections represent cell nuclei labeled with T0-PRO-3 iodide. Arrowheads, Optic disc. Scale bars, $160 \mu \mathrm{m}$.

ment is also reported in the Tlx $\mathrm{KO}$ telencephalon, and it is suggested that Tlx is involved in the dysregulation of proliferation (Roy et al., 2002; Land and Monaghan, 2003; Stenman et al., 2003), although the underlying molecular mechanism has not been elucidated. Our results indicate that Tlx is required for maintenance of each mitotic pool of RPCs to achieve the correct laminar arrangement, but not for specifying any particular retinal subtype, and its activities appear to be mediated by the regulatory expression of cyclin D1 and p2 ${ }^{\text {Kip } 1}$ during the mitotic cell cycles of RPCs. The loss of Tlx results in a reduced expression of cyclin D1, and an increased expression of $\mathrm{p} 27^{\mathrm{Kip} 1}$, and thus enhancing the differentiation mode of RPCs. Accordingly, the loss of Tlx leads to an initial increase in the number of early-generated progenies in the GCL and INL, whereas later on it leads to a decrease in the number of late-generated progenies in the ONL. Our study shows that Tlx is mostly expressed in the outer NBL where cyclin D1 is expressed, and not in the inner NBL where $\mathrm{p} 27^{\text {Kip } 1}$ is expressed. Previous studies reported the interaction between cyclin D1 and p2 $7^{\mathrm{Kip} 1}$ and provided evidence that cyclin D1 regulates the expression of $\mathrm{p} 27^{\mathrm{Kip} 1}$ (Geng et al., 2001; Green et al., 2003). Taken together, these results imply that Tlx might regulate the balance between the proliferation and differentiation of RPCs by primarily interacting with cyclin D1 in RPCs located in the outer NBL.

\section{Regulation of proliferation and differentiation of} retinal astrocytes

Several studies focused on the issues of how cell-extrinsic factors control the development of retinal astrocytes, however, cellintrinsic factors for the acquisition of astrocyte identity remained obscure (Mi and Barres, 1999; Wallace and Raff, 1999; Chu et al., 2001; Dakubo et al., 2003). In particular, cell-intrinsic factors that control the invasion and migration of retinal astrocytes remained to be defined. PDGF is one of the extrinsic factors expressed by RGCs and is implicated for the control of proliferation and migration of retinal astrocytes. A study in which the level of PDGF expression is altered showed that the extent of astrocyte network formation changes according to the number of astrocytes and the expression level of PDGF. Namely, PDGF inhibition results in a reduction and distortion of astrocyte network formation, whereas PDGF overexpression causes an increase in the number of astrocytes and a denser network. However, the cell-intrinsic mechanism that regulates the number and the network formation of astrocytes is not clear (Fruttiger et al., 1996). Our results show Tlx regulates the proliferation of astrocytes at both the optic disc and retinal surface, possibly by controlling cyclin D1 expression. Tlx $\mathrm{KO}$ retinas exhibit reduced cyclin D1 expression and mitotic activity in astrocytes, which presumably lead to a reduc- 
tion in the total astrocyte number in the retina. Moreover, the delay of astrocyte invasion and hypoplastic network formation in Tlx KO retinas suggests that Tlx is involved in the acquisition of the mature astrocyte phenotype. Taking into account the fact that in Tlx KO retinas PDGF is expressed by RGCs (data not shown) and PDGFR $\alpha$ is expressed by retinal astrocytes, Tlx appears to regulate the astrocyte-intrinsic developmental program in a manner independent of PDGF-mediated signaling. Furthermore, our EM analyses show that the cytoarchitectures of ILM and GCL are not disrupted in Tlx KO retinas at the time when astrocytes begin to migrate from the optic nerve, supporting the idea that the impaired astrocyte migratory behavior is not caused by the disturbance of the migratory paths that they normally take.

\section{Astrocyte differentiation and vasculogenesis in the retina}

One crucial aspect of astrocyte network formation in the retina is its involvement in vascular development (Gariano, 2003). In support of this idea, a study in which the extent of astrocyte network formation was increased by overexpressing PDGF showed an increase in vasculogenesis compatible to the extent of astrocyte network (Fruttiger et al., 1996). In Tlx KO retinas, the loss of astrocyte migration on most of the inner retinal surface is accompanied by the loss of retinal vasculature, as expected from the previous studies. Importantly, even in the region where astrocytes have migrated at later stages, little, if any, vessel formation is detected. This finding suggests that not only the acquisition of migratory capabilities but also the acquisition of inductive capabilities for vasculogenesis in astrocytes might be controlled by Tlx. Consistent with this idea, Tlx KO retinal astrocytes have lost their expression of R-cadherin, a critical component of retinal vasculogenesis (Dorrell et al., 2002), but continue to express other astrocyte-specific proteins, including $\operatorname{Pax} 2, \operatorname{PDGFR} \alpha$, and GFAP (Chu et al., 2001). Thus, Tlx might be involved in some aspects of differentiation and maturation of astrocytes, as is the case with the thyroid hormone receptor, another nuclear receptor that is involved in the terminal differentiation of oligodendrocyte precursor cells in the optic nerve (Baas et al., 2002).

In the mature retina, Tlx expression that is detected in RPCs during retinogenesis becomes confined to Müller cells that contain the molecular machinery essential for the support of retinal cells, including photoreceptor cells and RGCs (Willbold and Layer, 1998). Müller cells in Tlx KO retinas were found to be hypoplastic and in a reactive status during the postnatal stages. Nevertheless, Müller cells are present in Tlx KO retinas, suggesting that Tlx is not directly involved in the specification of Müller cells. A recent study showed that Tlx is critical for neural stem cells to give rise to neural progenies in adult brains (Shi et al., 2004). The expression of Tlx by Müller cells that can behave as retinal progenitor cells (Fischer and Reh, 2003) implies that Tlx might control the generation of retinal progeny from Müller cells in the adult retina. Future studies are necessary to see if Tlx controls the number of retinal progenies generated from Müller cells, as evidenced by our study in which the appropriate numbers of neuronal as well as astrocytic progenies are generated by the control of Tlx during the embryonic retinal development.

\section{References}

Baas D, Legrand C, Samarut J, Flamant F (2002) Persistence of oligodendrocyte precursor cells and altered myelination in optic nerve associated to retina degeneration in mice devoid of all thyroid hormone receptors. Proc Natl Acad Sci USA 99:2907-2911.

Cepko CL (1999) The roles of intrinsic and extrinsic cues and bHLH genes in the determination of retinal cell fates. Curr Opin Neurobiol 9:37-46.

Chow L, Levine EM, Reh TA (1998) The nuclear receptor transcription fac- tor, retinoid-related orphan receptor beta, regulates retinal progenitor proliferation. Mech Dev 77:149-164.

Chu Y, Hughes S, Chan-Ling T (2001) Differentiation and migration of astrocyte precursor cells and astrocytes in human fetal retina: relevance to optic nerve coloboma. FASEB J 15:2013-2015.

Dakubo GD, Wang YP, Mazerolle C, Campsall K, McMahon AP, Wallace VA (2003) Retinal ganglion cell-derived sonic hedgehog signaling is required for optic disc and stalk neuroepithelial cell development. Development 130:2967-2980

Dorrell MI, Aguilar E, Friedlander M (2002) Retinal vascular development is mediated by endothelial filopodia, a preexisting astrocytic template and specific R-cadherin adhesion. Invest Ophthalmol Vis Sci 43:3500-3510.

Dyer MA (2003) Regulation of proliferation, cell fate specification and differentiation by the homeodomain proteins prox 1 , six 3 , and chx10 in the developing retina. Cell Cycle 2:350-357.

Dyer MA, Cepko CL (2001a) p27Kip1 and p57Kip2 regulate proliferation in distinct retinal progenitor cell populations. J Neurosci 21:4259-4271.

Dyer MA, Cepko CL (2001b) Regulating proliferation during retinal development. Nat Rev Neurosci 2:333-342.

Dyer MA, Livesey FJ, Cepko CL, Oliver G (2003) Prox1 function controls progenitor cell proliferation and horizontal cell genesis in the mammalian retina. Nat Genet 34:53-58.

Ekstrom P, Sanyal S, Narfstrom K, Chader GJ, van Veen T (1988) Accumulation of glial fibrillary acidic protein in Muller radial glia during retinal degeneration. Invest Ophthalmol Vis Sci 29:1363-1371.

Fantl V, Stamp G, Andrews A, Rosewell I, Dickson C (1995) Mice lacking cyclin D1 are small and show defects in eye and mammary gland development. Genes Dev 9:2364-2372.

Fischer AJ, Reh TA (2003) Potential of Muller glia to become neurogenic retinal progenitor cells. Glia 43:70-76.

Fruttiger M (2002) Development of the mouse retinal vasculature: angiogenesis versus vasculogenesis. Invest Ophthalmol Vis Sci 43:522-527.

Fruttiger M, Calver AR, Kruger WH, Mudhar HS, Michalovich D, Takakura N, Nishikawa S, Richardson WD (1996) PDGF mediates a neuronastrocyte interaction in the developing retina. Neuron 17:1117-1131.

Gariano RF (2003) Cellular mechanisms in retinal vascular development. Prog Retin Eye Res 22:295-306.

Geng Y, Yu Q, Sicinska E, Das M, Bronson RT, Sicinski P (2001) Deletion of the p27Kip1 gene restores normal development in cyclin D1-deficient mice. Proc Natl Acad Sci USA 98:194-199.

Gouras P, Du J, Kjeldbye H, Kwun R, Lopez R, Zack DJ (1991) Transplanted photoreceptors identified in dystrophic mouse retina by a transgenic reporter gene. Invest Ophthalmol Vis Sci 32:3167-3174.

Green ES, Stubbs JL, Levine EM (2003) Genetic rescue of cell number in a mouse model of microphthalmia: interactions between Chx10 and G1phase cell cycle regulators. Development 130:539-552.

Haider NB, Jacobson SG, Cideciyan AV, Swiderski R, Streb LM, Searby C, Beck G, Hockey R, Hanna DB, Gorman S, Duhl D, Carmi R, Bennett J, Weleber RG, Fishman GA, Wright AF, Stone EM, Sheffield VC (2000) Mutation of a nuclear receptor gene, NR2E3, causes enhanced S cone syndrome, a disorder of retinal cell fate. Nat Genet 24:127-131.

Huxlin KR, Sefton AJ, Furby JH (1992) The origin and development of retinal astrocytes in the mouse. J Neurocytol 21:530-544.

Inoue C, Bae SK, Takatsuka K, Inoue T, Bessho Y, Kageyama R (2001) Math6, a bHLH gene expressed in the developing nervous system, regulates neuronal versus glial differentiation. Genes Cells 6:977-986.

Insua MF, Garelli A, Rotstein NP, German OL, Arias A, Politi LE (2003) Cell cycle regulation in retinal progenitors by glia-derived neurotrophic factor and docosahexaenoic acid. Invest Ophthalmol Vis Sci 44:2235-2244.

Ishibashi M, Ang SL, Shiota K, Nakanishi S, Kageyama R, Guillemot F (1995) Targeted disruption of mammalian hairy and Enhancer of split homolog-1 (HES-1) leads to up-regulation of neural helix-loop-helix factors, premature neurogenesis, and severe neural tube defects. Genes Dev 9:3136-3148.

Land PW, Monaghan AP (2003) Expression of the transcription factor, tailless, is required for formation of superficial cortical layers. Cereb Cortex 13:921-931.

Levine EM, Close J, Fero M, Ostrovsky A, Reh TA (2000) p27(Kip1) regulates cell cycle withdrawal of late multipotent progenitor cells in the mammalian retina. Dev Biol 219:299-314.

Li X, Perissi V, Liu F, Rose DW, Rosenfeld MG (2002) Tissue-specific regu- 
lation of retinal and pituitary precursor cell proliferation. Science 297:1180-1183.

Livesey FJ, Cepko CL (2001) Vertebrate neural cell-fate determination: lessons from the retina. Nat Rev Neurosci 2:109-118.

Ma C, Papermaster D, Cepko CL (1998) A unique pattern of photoreceptor degeneration in cyclin D1 mutant mice. Proc Natl Acad Sci USA 95:9938-9943.

Mangelsdorf DJ, Thummel C, Beato M, Herrlich P, Schutz G, Umesono K, Blumberg B, Kastner P, Mark M, Chambon P, Evans RM (1995) The nuclear receptor superfamily: the second decade. Cell 83:835-839.

Marquardt T (2003) Transcriptional control of neuronal diversification in the retina. Prog Retin Eye Res 22:567-577.

Marquardt T, Gruss P (2002) Generating neuronal diversity in the retina: one for nearly all. Trends Neurosci 25:32-38.

Marquardt T, Ashery-Padan R, Andrejewski N, Scardigli R, Guillemot F, Gruss P (2001) Pax6 is required for the multipotent state of retinal progenitor cells. Cell 105:43-55.

Mi H, Barres BA (1999) Purification and characterization of astrocyte precursor cells in the developing rat optic nerve. J Neurosci 19:1049-1061.

Monaghan AP, Bock D, Gass P, Schwager A, Wolfer DP, Lipp HP, Schutz G (1997) Defective limbic system in mice lacking the tailless gene. Nature 390:515-517.

Mudhar HS, Pollock RA, Wang C, Stiles CD, Richardson WD (1993) PDGF and its receptors in the developing rodent retina and optic nerve. Development 118:539-552.

Ohnuma S, Hopper S, Wang KC, Philpott A, Harris WA (2002) Coordinating retinal histogenesis: early cell cycle exit enhances early cell fate determination in the Xenopus retina. Development 129:2435-2446.

Peterson RE, Fadool JM, McClintock J, Linser PJ (2001) Muller cell differentiation in the zebrafish neural retina: evidence of distinct early and late stages in cell maturation. J Comp Neurol 429:530-540.

Provis JM (2001) Development of the primate retinal vasculature. Prog Retin Eye Res 20:799-821.

Roy K, Thiels E, Monaghan AP (2002) Loss of the tailless gene affects forebrain development and emotional behavior. Physiol Behav 77:595-600.
Shi Y, Chichung Lie D, Taupin P, Nakashima K, Ray J, Yu RT, Gage FH, Evans RM (2004) Expression and function of orphan nuclear receptor TLX in adult neural stem cells. Nature 427:78-83.

Sicinski P, Donaher JL, Parker SB, Li T, Fazeli A, Gardner H, Haslam SZ, Bronson RT, Elledge SJ, Weinberg RA (1995) Cyclin D1 provides a link between development and oncogenesis in the retina and breast. Cell 82:621-630.

Stenman JM, Wang B, Campbell K (2003) Tlx controls proliferation and patterning of lateral telencephalic progenitor domains. J Neurosci 23:10568-10576.

Stuermer CA, Bastmeyer M (2000) The retinal axon's pathfinding to the optic disk. Prog Neurobiol 62:197-214.

Thummel CS (1995) From embryogenesis to metamorphosis: the regulation and function of Drosophila nuclear receptor superfamily members Cell 83:871-877.

Wallace VA, Raff MC (1999) A role for Sonic hedgehog in axon-to-astrocyte signalling in the rodent optic nerve. Development 126:2901-2909.

Willbold E, Layer PG (1998) Muller glia cells and their possible roles during retina differentiation in vivo and in vitro. Histol Histopathol 13:531-552.

Yanagi Y, Takezawa S, Kato S (2002) Distinct functions of photoreceptor cellspecific nuclear receptor, thyroid hormone receptor beta2 and CRX in one photoreceptor development. Invest Ophthalmol Vis Sci 43:3489-3494.

Young KA, Berry ML, Mahaffey CL, Saionz JR, Hawes NL, Chang B, Zheng QY, Smith RS, Bronson RT, Nelson RJ, Simpson EM (2002) Fierce: a new mouse deletion of Nr2e1; violent behaviour and ocular abnormalities are background-dependent. Behav Brain Res 132:145-158.

Yu RT, McKeown M, Evans RM, Umesono K (1994) Relationship between Drosophila gap gene tailless and a vertebrate nuclear receptor Tlx. Nature 370:375-379.

Yu RT, Chiang MY, Tanabe T, Kobayashi M, Yasuda K, Evans RM, Umesono $\mathrm{K}$ (2000) The orphan nuclear receptor Tlx regulates Pax2 and is essential for vision. Proc Natl Acad Sci USA 97:2621-2625.

Zhang XM, Yang XJ (2001) Regulation of retinal ganglion cell production by Sonic hedgehog. Development 128:943-957. 